\title{
Reverberações da aprendizagem de professores de matemática em uma comunidade fronteiriça entre universidade-escola
}

\section{Reverberations of learning by Math teachers in a borderland community between university-school}

\author{
Vanessa Moreira Crecci* \\ Dario Fiorentini*
}

\begin{abstract}
RESUMO
Este artigo tem como foco de estudo a aprendizagem docente situada em uma comunidade fronteiriça entre escola e universidade que congrega professores da escola, formadores de professores, futuros professores e pesquisadores interessados em discutir e investigar práticas de ensinaraprender matemática. Atenção especial de análise será dada às reverberações dessa aprendizagem no desenvolvimento profissional do professor, sobretudo na mudança de sua prática. Além de discutir os conceitos de aprendizagem situada e o desenvolvimento profissional, trazemos para análise da aprendizagem docente e de suas reverberações o caso do professor Roberto que participou de uma comunidade fronteiriça entre escola e universidade. A metodologia deste estudo ocorreu com base na pesquisa narrativa, que compreende um processo tridimensional de produção e análise dos textos de campo e de pesquisa, envolvendo temporalidade (diacronia), interações pessoais e sociais e o lugar (cenário) onde se situa o fenômeno a ser investigado e narrado, tendo sido produzida uma análise narrativa do desenvolvimento profissional de Roberto. Os resultados apontaram que a participação e reificação de Roberto no seio da comunidade fronteiriça reverberaram em sua prática na escola, tendo produzidas diferentes compreensões sobre o ensinaraprender mate-

* Universidade Estadual de Campinas. Faculdade de Educação. Campinas, São Paulo, Brasil. E-mail: vancrecci@gmail.com. https://orcid.org/0000-0001-6491-503X. E-mail: dariofiore@terra. com.br. https://orcid.org/0000-0001-5536-0781.
\end{abstract}


mática e projetado outro modo de ser/estar professor e de desenvolver-se profissionalmente.

Palavras-chave: Comunidade fronteiriça. Reverberações. Aprendizagem situada. Professor que ensina matemática. Desenvolvimento profissional.

\begin{abstract}
This article focuses on teacher learning in a borderland community between school and university, which brings together teachers from the school, teacher trainers, future teachers and researchers interested in discussing and investigating practices of teaching and learning mathematics. A special attention is given to the reverberations of this learning in the professional development of the teachers, especially regarding changes in their practices. Besides discussing the concepts of situated learning, professional development and reverberation, we bring to the analysis the case of Roberto, a teacher who participated in a teaching community with borderland characteristics. The methodology of this study was based on narrative research, which comprises a three-dimensional process of production and analysis of research and field texts, involving temporality, personal and social interactions and the place (scenario) where the phenomenon to be investigated and narrated is situated. The study also analyzed Roberto's professional development. The results showed that his participation and reification within the borderland community reverberated in his practice at school, producing different understandings about teaching and learning mathematics, as well as designing another way of being a teacher and developing professionally.
\end{abstract}

Keywords: Borderland community. Reverberations. Situated learning. Math teachers. Professional development.

\title{
Introdução
}

Há alguns anos, os conceitos e os focos recorrentes de análise de nossos estudos têm sido a aprendizagem e o desenvolvimento profissional, a identidade e a profissionalidade do professor que ensina matemática, principalmente em contextos de comunidades profissionais voltadas ao ensino e à aprendizagem, compreendidas por nós como comunidades de prática no sentido de Lave e Wenger $(1991,2002)$ e Wenger (2001). Um dos principais contextos desses estudos tem sido o Grupo de Sábado (GdS) concebido por Fiorentini (2009) como comunidade de prática docente de educadores matemáticos que con- 
grega professores da escola, formadores de professores, futuros professores e pesquisadores da universidade interessados em discutir as práticas de ensinar e aprender matemática na escola básica.

Mais recentemente, Fiorentini (2013) tem caracterizado o GdS como uma comunidade fronteiriça que se diferencia das comunidades acadêmicas ou escolares, principalmente por se situar num espaço fronteiriço entre a universidade e a escola básica. Nessa compreensão, a fronteira é um espaço livre onde podem se reunir interessados de comunidades diferentes que se aventuram na construção e problematização do conhecimento. Trata-se de uma comunidade que não é regulada institucionalmente nem pela escola, nem pela universidade; possuindo uma agenda livre de estudo e trabalho, e voltada aos interesses dos professores da escola, tendo os formadores e acadêmicos da universidade como colaboradores e investigadores.

Em uma comunidade fronteiriça é geralmente adotada uma prática colaborativa e de apoio mútuo, podendo também desenvolver práticas investigativas. Esse cenário de aprendizagem e desenvolvimento docente tem-se constituído num contexto privilegiado de pesquisas, e seus membros têm sido colaboradores de nossos estudos, sendo muitas vezes coautores.

A fronteira é um lugar de perigo e de transgressão do instituído na escola e na academia. Por isso, devido às diferentes origens de seus participantes, os encontros tendem a ser entremeados por narrativas de acontecimentos que ocorrem nas comunidades de origem de cada um, sendo estes acontecimentos problematizados e desnaturalizados pela comunidade. Nesse sentido, "o que se produz e se aprende nessa comunidade tem forte impacto na vida pessoal e profissional de cada participante" (FIORENTINI, 2013, p. 156-157).

Neste artigo, pretendemos analisar e compreender a aprendizagem docente e o desenvolvimento profissional de um professor escolar participante do GdS, destacando principalmente as reverberações dessa participação numa comunidade fronteiriça em suas práticas profissionais, sobretudo no modo como projeta e desenvolve a docência. A seguir, discutimos conceitualmente a aprendizagem docente situada em comunidades de prática, para então trazermos a metodologia da pesquisa e, por fim, narrar e analisar as reverberações dessa aprendizagem no desenvolvimento profissional do professor e em sua prática escolar.

\section{Aprendizagem docente situada em comunidades de prática}

A concepção de aprendizagem utilizada neste estudo é embasada na teoria social da aprendizagem, para a qual toda aprendizagem é situada em 
uma prática social específica e esta não pode ser transferida ou transposta para outros contextos (LAVE; WENGER, 1991). Os saberes em uma comunidade de prática são produzidos e evidenciados através de formas compartilhadas de fazer e entender dentro da comunidade, as quais resultam de dinâmicas de negociação que envolvem participação e reificação na prática da comunidade (FIORENTINI, 2013, p. 157).

A participação pressupõe um processo de negociação e renegociação de significados situados no mundo. Isso implica que "o entendimento e a experiência estão em constante interação e são mutuamente constitutivos" (LAVE; WENGER, 2002, p. 168-169).

Em síntese, a aprendizagem situada é um fenômeno social, coletivo, interativo e ocorre mediante participação em comunidades de prática. Sendo, assim, é compreendida também como um fenômeno carregado de ideologias e valores que emergem da participação direta em uma prática social, independente de esta ser organizada com o propósito de ensinar algo a alguém.

Wenger (2001) afirma que uma comunidade de prática tem três características básicas: o compromisso mútuo, uma prática conjunta e o interesse comum. No contexto do GdS, temos compreendido que o compromisso mútuo reside no engajamento e participação efetiva nas práticas conjuntas de reflexão e/ou investigação sobre a prática de ensinaraprender ${ }^{1}$ matemática nas escolas (interesse comum).

O conceito de participação, na perspectiva de Wenger (2001), compreende o processo pelo qual os sujeitos de uma comunidade compartilham, discutem e negociam significados sobre o que fazem, dizem e sentem. Dessa maneira, participar de uma comunidade de prática significa engajar-se na atividade própria da comunidade como membro atuante e produtivo; isso implica também apropriar-se da prática, dos saberes e dos valores cultivados pelo grupo. Participar de uma comunidade significa, portanto, aprender sua prática comum. Compreende-se, assim, a participação como um processo pelo qual os membros de uma comunidade de prática compartilham, discutem e negociam significados sobre o que fazem, falam, pensam e produzem conjuntamente (FIORENTINI, 2009).

Embora toda a aprendizagem situada em uma comunidade de prática não possa ser transferida ou transposta para outros contextos, o que aí se aprende sempre tem impacto pessoal e social, isto é, pode reverberar na constituição do

1 Utilizamos a palavra composta ensinaraprender para expressar, de acordo com Carvalho e Fiorentini (2013, p. 11), "a complexidade e a dialética de como percebemos a relação entre o ensino e a aprendizagem". Ou seja, "o ensino só tem sentido, se promover aprendizagens". Além disso, "embora o professor, ao ensinar, tenha como meta determinada aprendizagem, [...] as aprendizagens podem ser múltiplas e nem sempre alinhadas às expectativas que o professor estabelece para o estudante". 
sujeito ou em suas práticas em outros cenários de participação, principalmente a partir do questionamento, da problematização e (re)significação das práticas das comunidades de origem de cada um. Reverberação é um conceito que tem origem na Física e é utilizado para expressar a persistência do efeito audível de um som, mesmo após a fonte de emissão do som ter sido cessada. Assim podemos dizer que a mudança de sua prática na escola ou o desenvolvimento profissional do professor são reverberações daquilo que acontece na comunidade fronteiriça, isto é, resulta de sua participação e reificação nessa comunidade.

O conceito de desenvolvimento profissional do professor, por outro lado, pode ser considerado como um movimento que perpassa ao longo de toda sua vida e que ocorre em espaços formais e não formais de formação. Se considerarmos o desenvolvimento profissional docente em comunidades de aprendizagem docente, podemos afirmar que este ocorre à medida que os professores realizam, conjuntamente, questionamentos sobre suas próprias práticas, teorizam e sistematizam sobre elas. A partir de práticas investigativas em comunidades, os professores podem planejar atividades a serem realizadas em sala de aula, desenvolver material didático e escrever narrativas sobre os modos de ensinar e aprender. Podem ainda compartilhar e analisar atividades desenvolvidas em sala de aula, realizar estudos a partir de questões emergentes da prática pedagógica e, inclusive, ressignificar a literatura da área etc.

Quanto às comunidades de aprendizagem docente, Cochran-Smith e Lytle apontam que estas se referem tanto a um espaço intelectual quanto a um grupo particular de pessoas e, algumas vezes, um espaço físico. Neste sentido, comunidades são configurações intelectuais, sociais e organizacionais que apoiam o crescimento profissional contínuo dos professores, possibilitando oportunidades para os docentes pensarem, conversarem, lerem e escreverem sobre seu trabalho diário, incluindo os seus contextos sociais, culturais e políticos de forma planejada e intencional (COCHRAN-SMITH; LYTLE, 2002).

No que se refere às produções dos participantes em uma comunidade de prática, Wenger (2001) afirma que estas resultam de um processo de reificação, o qual significa tornar algo em coisa. Entretanto, isso não significa ser essa coisa algo concreto ou material. Fiorentini compreende que tais reificações não se referem apenas a objetos materiais ou concretos, podendo ser, também, "conceitos, ideias, rotinas, registros escritos e teorias que dão sentido às práticas da comunidade" (2013, p. 157). Nesse sentido, as reificações dos grupos colaborativos podem ser percebidas e conferidas tanto nas práticas escritas que realizam, bem como, nos momentos coletivos de produção e negociação de significados sobre a prática de ensinar e aprender matemática nas escolas.

Na tese defendida por Crecci (2016), realizada no contexto no GdS, tendo como foco de estudo as experiências de desenvolvimento profissional e a constitui- 
ção da profissionalidade de educadores matemáticos que participam desse grupo, notou-se que as experiências realizadas por educadores matemáticos neste espaço foram continuamente problematizadas e (re)significadas pelo coletivo do grupo e reverberam em outras comunidades - sejam escolares sejam acadêmicas - e, sobretudo, no desenvolvimento profissional e nas identidades dos próprios participantes.

\section{Contexto do estudo e metodologia da pesquisa}

Fundado em 1999, o GdS conta com a participação de professores que ensinam matemática na escola básica, geralmente interessados em estudar, refletir e investigar sobre ensinaraprender matemática nesse contexto. Conta também com a participação de professores universitários, mestrandos e doutorandos, interessados em investigar o processo de aprendizagem e desenvolvimento profissional de professores em um contexto colaborativo de reflexão e investigação sobre a prática.

Os encontros do grupo acontecem quinzenalmente aos sábados. A agenda do grupo é definida de acordo com as demandas dos professores. Embora, o espaço físico utilizado seja a universidade, esse espaço e essa agenda não são controlados institucionalmente pela universidade. São os próprios professores da escola que negociam o que querem estudar, discutir ou investigar nesta comunidade. Só depois de definirem essas demandas é que os universitários se mobilizam para trazer/promover mediações de natureza teórica ou do mundo da academia, desde que estas possam ajudar a compreender e problematizar as demandas dos professores.

Carvalho e Fiorentini (2013) consideram que no GdS não há os que ensinam e os que aprendem, todos ensinam e todos aprendem, a partir de seus horizontes. Cada um de nós tem seu próprio horizonte. Na Figura 1, o GdS está disposto entre a escola e a universidade, porém não é regulado por nenhum dos dois contextos, uma vez que tem suas próprias normativas.

FIGURA 1 - GRUPO DE SÁBADO, ENTRE DOIS MUNDOS

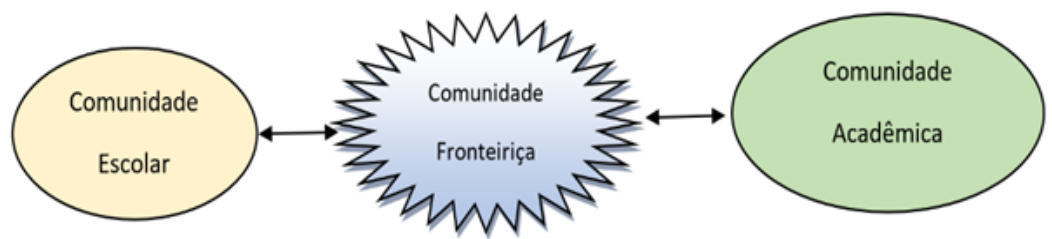

FONTE: Crecci (2016). 
A escolha de Roberto justifica-se por ele ser, no início da pesquisa de campo, em 2012, o professor mais antigo do grupo e sem pretensão de seguir uma carreira acadêmica, como muitas vezes aconteceu com os participantes do grupo.

De acordo com a teoria social da aprendizagem (LAVE; WENGER, 1991), a aprendizagem baseada em comunidade pode ser melhor descrita e analisada examinando a história de participação e reificação dos participantes nessa comunidade. E por ser esta história um fenômeno narrativo, optamos pela metodologia da pesquisa narrativa (CLANDININ; CONNELLY, 2011) que compreende um processo tridimensional de produção e análise de textos de campo e de pesquisa, envolvendo temporalidade (diacronia), interações pessoais e sociais e o lugar (cenário) onde se situa o fenômeno a ser investigado e narrado. Essa relação tridimensional contempla a complexidade da narrativa que ganha amplitude e significação à medida que o pesquisador-narrador entrelaça as múltiplas vozes que participam da experiência formativa, explicitando "a estrutura através da descrição do cenário e da trama, localizados em um tempo e em um espaço" (MARQUESIN; PASSOS, 2009, p. 223).

Um dos aspectos mais presentes da pesquisa narrativa é a temporalidade das situações vividas, contadas e (re)contadas. Clandinin e Huber (2010) apontam que pesquisadores narrativos precisam observar a temporalidade de seus participantes, bem como a temporalidade de espaços, lugares e eventos. Ainda, segundo as autoras, a importância da temporalidade na pesquisa narrativa vem das visões filosóficas de experiência.

Bondía-Larrosa (1996) aponta que a experiência envolve a narrativa, e narrativamente cada um expõe sua experiência. Clandinin e Connelly argumentam que os acontecimentos estudados estão em transição temporal, e os autores têm como questão central a temporalidade, uma vez que têm como "certo que localizar as coisas no tempo é a forma de pensar sobre elas". Adiante, apontam: "quando vemos um evento, pensamos sobre ele não como algo que aconteceu naquele momento, mas sim como uma expressão de algo acontecendo ao longo do tempo" (CLANDININ; CONNELLY, 2011, p. 63).

Acerca da percepção de tempo dos participantes, pesquisadores narrativos participam das formas temporais dos pontos de vista dos participantes em relação ao passado, presente e futuro das pessoas, dos lugares, das coisas e dos eventos em estudo. Bakhtin (2011, p. 394) defende que "o indivíduo não tem apenas meio e ambiente, tem também horizonte próprio". Ouvir o que os participantes de nossas pesquisas têm a nos dizer pode nos levar à compreensão da "expressão do indivíduo e a expressão das coletividades, dos povos, das épocas, da própria história, com seus horizontes e ambientes" (BAKHTIN, 2011, p. 395).

Assim como a temporalidade, a sociabilidade deve permear as narrativas nessa perspectiva. Para Clandinin e Huber (2010, p. 5), pesquisadores narrativos 
atendem simultaneamente as condições pessoais e sociais. Por condições pessoais, elas compreendem "os sentimentos, esperanças, desejos, reações estéticas e dispositivos morais dos participantes".

E, por "sociabilidade", as autoras se referem aos contextos nos quais as experiências pessoais são constituídas, compreendidos em termos de narrativas culturais, sociais, institucionais e linguísticas. Uma segunda dimensão de sociabilidade vincula-se ao fato de que os pesquisadores narrativos não podem subtrair a eles próprios da pesquisa. Esse tipo de pesquisa acontece em relação ao outro, considerando o sujeito nas interações de que participa.

Ainda que com alteridade e com as amenidades possíveis pelas negociações com os participantes da pesquisa, "a consciência do autor é consciência de uma consciência" (BAKHTIN, 2011, p. 32). Parece-me, assim, que os limites estéticos da minha pesquisa, da minha perspectiva, das minhas visões e interações coadunam com o fato de que não se pode reificar as interações vividas realmente - essa, sim, uma atividade de reconto.

O diferencial da pesquisa narrativa é que reconhecemos que viver, contar e recontar é um processo artesanal, por sua gênese, único para compreender experiências vividas, o que não se pode é subtrair o autor do estudo. Por um lado, voltando-nos para nosso interior, devemos compreender nossas emoções, nossas reações estéticas e responsabilidades morais; por outro lado, voltando-nos para nosso exterior, devemos compreender o que está acontecendo, os eventos, as pessoas e suas experiências (CLANDININ, 2013).

Em 2006, Clandinin e Connelly (2011, p. 480) definiram lugar como "o local específico e concreto, físico e de fronteiras topológicas, locais e sequência de locais onde a pesquisa e eventos acontecem". Para Clandinin e Huber (2010), pesquisadores narrativos possuem suas identidades inexoravelmente conectadas com as experiências constituídas em determinados locais e com as histórias que são contadas em locais específicos ou com as histórias que contamos sobre as experiências que vivemos em determinados contextos.

Na perspectiva da pesquisa narrativa, textos de campo podem ter variadas fontes de dados para que possamos "falar sobre o que é considerado dados de pesquisa" (CLANDININ; CONNELLY, 2011, p. 143). Para Clandinin e Connelly, os dados das pesquisas narrativas podem ser notas de campo da experiência, registros em diário, transcrições de entrevistas, observações, relato de histórias, cartas, autobiografias e documentos, como planos de aula e boletins informativos, anotações pessoais etc.

Muitas vezes, não nos damos conta de que o processo de produção desses dados é também interpretativo e envolve análise do pesquisador. Clandinin e Connelly (2011, p. 134) destacam que: 
[...] considerando que os textos são nossa forma de falar sobre o que é considerado como dados na pesquisa narrativa e tendo em vista que os dados tendem a carregar uma ideia de representação objetiva de uma experiência de pesquisa, é importante notar quão imbuídos de interpretação são os textos de campo.

Em Crecci (2016) os textos de campo compreenderam um diário de campo com notas das reuniões do GdS; memórias ${ }^{2}$ das reuniões do GdS, escritas de 1999 a 2015; materiais publicados sobre a própria comunidade e por ela; transcrição de encontros do grupo entre os anos de 2007 e 2015; transcrição de seis entrevistas semiestruturadas com os participantes da pesquisa; e documentos cedidos pelos próprios participantes da pesquisa (anotações pessoais, relatórios e publicações).

Um dos desafios que vivemos, quando nos aventuramos pelos caminhos da pesquisa narrativa, é transformar os textos de campo em material ou textos de pesquisa. Isso implica tratar esses textos (material de pesquisa) de modo narrativo, isto é, interpretá-los e analisá-los narrativamente.

Clandinin e Connelly (2011) afirmam que, durante a composição do texto de pesquisa, é comum que as justificativas, a compreensão do fenômeno, o método, a interpretação, a análise, as confrontações teóricas e a própria opção pelo tipo de texto de pesquisa que o pesquisador deseja compor passem a ocupar atenção especial do pesquisador narrativo. Isso exige dele cuidado ético, dando início a outro processo, também complexo, de negociar a saída do campo. Quando compomos textos de pesquisa, criamos muitas vezes cenários próprios de significação e compreensão nos quais os professores são protagonistas principais.

Os textos de campo utilizados para a composição da narrativa foram constituídos por um diário de notas da primeira autora, a partir de sua participação nas reuniões do GdS; artigos e textos publicados sobre e pela comunidade; memórias e transcrições de encontros do grupo; e entrevistas da primeira autora com os participantes da pesquisa.

A seguir, apresentamos a composição narrativa de aprendizagem e desenvolvimento profissional do professor Roberto.

2 São textos escritos sobre os acontecimentos dos encontros. Como têm um tom mais narrativo, habitualmente, passamos a chamar as atas de "memórias". 


\section{Narrativa de aprendizagem e desenvolvimento profissional do professor Roberto}

Roberto é professor na rede municipal de Campinas há mais de 16 anos. Desde 2006, participa do GdS. Atualmente leciona matemática para os anos finais do segundo segmento do ensino fundamental.

Em 2012, contando com a colaboração de participantes do grupo, Roberto iniciaria um trabalho com a escrita em aulas de matemática. Inicialmente, o professor disparou o seguinte e-mail na lista:

Estou com dois $6^{\circ} \mathrm{s}$ anos este ano e como já era esperado apresentam muita dificuldade com o algoritmo da divisão. Não estou nem pensando na ideia da divisão, mas apenas no domínio e entendimento do algoritmo. Estou retomando as "casas decimais", já que o nosso algoritmo trabalha com a divisão separada por cada casa. Também peço que eles escrevam passo a passo como fazem a divisão, na tentativa de que reflitam sobre o que fazem. Quero utilizar o material dourado e/ou o ábaco de hastes, para que eles visualizem no algoritmo aquilo que fazem naturalmente em uma divisão. Alguém tem alguma outra sugestão? (Prof. Roberto, E-mail, 10 mar. 2013).

A preocupação de Roberto com seus alunos e suas aprendizagens, lançada na lista de e-mail do grupo, mobilizou seus membros, que interagiram, desencadeando várias reflexões, trocas e sugestões. Em outro momento, Roberto escreveu:

Tentarei colocar um pouco das minhas observações e impressões sobre a divisão, ou melhor, sobre o nosso algoritmo da divisão. Claro que considero importantes os vários conceitos e ideias envolvidas nela, mas não é este o objeto de minhas inquietações. Professores, que já deram aula para um $6^{\circ}$ ano, sabem das dificuldades que os alunos apresentam com o algoritmo da divisão. [...] Tenho até uma hipótese sobre esta dificuldade: penso que o algoritmo da divisão necessita de um domínio apurado da multiplicação (e/ou adição) e da subtração (Prof. Roberto, E-mail, 23 mar. 2013). 
$\mathrm{Na}$ lista do grupo, as discussões geradas versaram sobre diferentes aspectos do ensino da divisão: questionamentos sobre o ensino do algoritmo; processo mecânico; uso da calculadora; expectativas da família; o que os professores querem que seus alunos aprendam; tipos de avaliação que os alunos realizam; formação inicial de professores; conceitos de divisão; outras experiências e sugestões de leituras e de material concreto (BARBUTTI; PROENÇA; CRECCI, 2014).

As colaborações mobilizadas por diferentes participantes no $e$-mail foram apresentadas nos encontros presenciais do GdS. Naquele período, organizamos encontros para que Roberto expusesse as atividades desenvolvidas em duas turmas de sextos anos, abordando o algoritmo da divisão, o uso do material dourado e do ábaco na realização da divisão. Um aspecto interessante é que, em cada uma dessas atividades, realizadas em grupos, os alunos também tiveram que escrever como fizeram a divisão (BARBUTTI; PROENÇA; CRECCI, 2014). Em um dos encontros de abril daquele ano, Roberto apresentou as produções escritas dos alunos:

Roberto - Comecei a pedir para que as crianças escrevessem sobre como fazem a divisão. Fica muito marcante aquele procedimento tradicional: abaixa número, procura na tabuada. Percebo que eles não têm entendimento do que está acontecendo no algoritmo.

Participante do grupo - Quando eles escrevem, você percebe isso?

Roberto - Sim, aparece.

Participante do grupo - Então, expressam um modo mais procedimental do que de compreensão conceitual da divisão?

Roberto - Para compreender que eles conseguem fazer a divisão, desenvolvi atividades com o material dourado. E sabemos que socialmente eles convivem com a divisão. Os alunos fizeram as trocas normalmente, disse que não poderia sobrar nenhuma peça. Já nos escritos dos alunos apareceram os procedimentos: "procuro na tabuada", "coloco embaixo da chave", "multiplico", "coloco embaixo, tiro e abaixo o número". Percebo que são expressões que não falam do significado do que fazem. (Transcrição de encontro, ago. 2012). 
Tomando os escritos dos alunos, o professor teceu diversos questionamentos:

Como surgiram as falhas de procedimentos dos alunos? Os alunos estão preparados para entender as abstrações do algoritmo? Será que conhecem a multiplicação e subtração suficientemente? E o nosso sistema de numeração com base 10? Será que os alunos compreendem que, no algoritmo, a separação é feita por cada "casa" numérica? (Prof. Roberto, Apresentação, ago. 2012).

Em decorrência desse trabalho com a escrita, no I Simpósio de Grupos Colaborativos e de Aprendizagem do Professor que Ensina Matemática, o professor destacou que "a construção da divisão nos $6^{\circ}$ s anos está em processo ainda. Por isso tenho que trabalhar, pelo que percebi, mais o nosso sistema de numeração. Será que o ábaco é o melhor material? Mas isso é outra questão para o GdS" (Prof. Roberto, Apresentação, ago. 2012).

No contexto do GdS, ocorreram dois momentos significativos nos quais o grupo se dedica a investigar e a utilizar a escrita em aulas de matemática. Em um primeiro momento, o objetivo era o professor usar a escrita para contar experiências de sala de aula. Isso ocorreu logo no início dos anos 2000. Essa fase foi amplamente investigada por Pinto (2002). Em uma segunda fase, a partir de 2004, a escrita do aluno também passou a ser de interesse do GdS, dessa vez no que se refere ao seu uso em aulas de matemática.

Ao inserir a escrita em suas aulas de matemática, Roberto evidenciou que estava incorporando em suas aulas, uma prática muito valorizada e praticada no interior do GdS. Desde a fundação do GdS, os professores do grupo se mobilizavam a instigar seus alunos da escola a escrever o que faziam, pensavam e significavam nas atividades matemáticas de sala de aula. Percebemos que o professor Roberto levou algum tempo para incorporar em seu cotidiano docente tal prática. Com o passar do tempo, uma prática reificada no seio daquela comunidade fronteiriça - no caso a prática do uso da escrita em aulas de matemática - reverberou na atividade de sala de aula do professor. Wenger-Trayner e Wenger-Trayner (2016) destacam que as comunidades de prática podem ser compreendidas como cenários de aprendizagens complexas. Esses autores têm destacado que os participantes das comunidades possuem diferentes habilidades e formas de participação, isto é, aprendem de diferentes modos. Acrescentaríamos, ainda, a ideia de que os participantes das comunidades, sobretudo daqueles de natureza fronteiriça - sem vínculos institucionais -, lidam com o tempo de diferentes maneiras. 
Em entrevista, Roberto diversas vezes se remeteu a experiências de outros contextos. Nesse sentido, revelou que durante a graduação não se dava conta sobre a importância das disciplinas pedagógicas. Segundo ele, foi no GdS que encontrou respaldo teórico para seu campo de atuação.

Eu nem sabia a diferença entre matemática e educação matemática. Para você ter uma ideia, passei quatro anos de licenciatura sem saber essa diferença. Eu gosto da matemática pura, tanto que fui para o mestrado. Eu acho bonita a matemática! Mas isso me fez questionar muito, aquele sonho de professor que gosta de matemática, que quer que o aluno seja matemático, que o aluno demonstre e ache bonito aquilo. Então, quando eu me dei conta de que existe a educação matemática, comecei a questionar: a matemática é bonita para quem? De repente, esta não é a visão do aluno (Prof. Roberto, entrevista).

Roberto graduou-se, nos anos de 1990, em licenciatura e bacharelado em um curso de matemática oferecido por uma comunidade rigorosa e exigente. Subjacente às práticas socialmente naturalizadas desse contexto, com altos índices de reprovação nas disciplinas de formação matemática e a desvalorização (com reduzida carga horária) das disciplinas de formação didático-pedagógica, parecia estar implícita a crença de que para ensinar matemática, bastava ao futuro professor saber muita matemática. Para essa comunidade de matemáticos, apropriar-se de conteúdos matemáticos era o que mais importava na formação inicial e no DP de professores. Desse modo, "a prática do professor de matemática pode ser vista como essencialmente prática, bastando a ele apenas o domínio técnico-formal do conhecimento matemático" (FIORENTINI; OLIVEIRA, 2013, p. 920). Nessa comunidade, Roberto destacou-se por sua eficiência ao conseguir ser aprovado com boas notas nas disciplinas específicas da matemática, tendo, logo após a conclusão da graduação, ingressado no mestrado em Matemática Pura.

A experiência de participação constituída por Roberto no contexto do GdS nos levou a questioná-lo sobre que tipo de mudança vislumbrava ter ocorrido em sua prática, como participante no GdS.

Acredito que o principal aprendizado é o olhar sobre o aluno. Não vejo mais apenas o resultado final que o aluno apresenta em vista daquilo que foi planejado e marcado como objetivo. Diria até que, muitas vezes, o resultado final fica em segundo plano. Agora, valorizo o caminho que o aluno fez na tentativa de chegar àquele objetivo. Aprendi a olhar para a riqueza deste processo de aprendizado. (Prof. Roberto, entrevista). 
No GdS, Roberto acredita que "encontrei meu semelhante. Percebi que as dificuldades que temos em sala de aula, que achava que eram minhas apenas, são gerais. Isso dá um pouquinho mais tranquilidade para trabalhar". Sobre esse ambiente de diálogo e análise da prática, Roberto aponta, com certa crítica, que "não ocorre na Escola e não é oferecido pela rede municipal um espaço para isto" e, além disso, declara que é no grupo que "sou valorizado como profissional" (Prof. Roberto, entrevista).

Acerca de seu sentimento sobre participar do GdS, despontam aspectos de diferentes naturezas, revelando que, nesse espaço,

Posso compartilhar minhas experiencias e ouvir outras, questionar e tirar dúvidas sobre minha prática, obter subsídios teóricos e indicações de leituras. Receber informações diretas sobre a gestão pública do ensino e de suas novas tendências, discutindo e tentando interferir nestas políticas. Posso desabafar e falar sobre minhas angústias de professor (Prof. Roberto, entrevista).

Mediante identificação com os participantes e com as práticas do grupo, Roberto apresenta indícios de ter modificado suas percepções e seu modo de ser professor. Crecci (2016) revela que reverberações decorrentes da participação em uma comunidade de prática, caracterizada como comunidade fronteiriça, também se evidenciam nos próprios modos de ser/estar como educadores matemáticos de seus participantes, destacando-se a postura problematizadora e investigativa sobre a própria prática, sobre as políticas públicas que a condicionam e sobre as possibilidades e os limites dos conhecimentos científicos, curriculares e didáticos pedagógicos tanto da própria escola como de outros contextos. Considerando que as reificações, segundo Fiorentini (2009), também são as ideias e projeções constituídas em uma comunidade de prática, esse modo de ser e estar professor pode ser considerado uma reverberação da participação de Roberto no GdS.

Outro indício de que as reificações do GdS reverberam na prática profissional de Roberto foi que, ao conhecer as experiências de colegas do grupo, "passei a utilizar sistematicamente materiais como o Cuisenaire e Material Dourado em minhas aulas." (Prof. Roberto, entrevista). Entretanto, pela interlocução com os acadêmicos do grupo, compreendeu não apenas as possibilidades, mas também os limites do uso dos materiais concretos. Percebeu que, dependendo do modo como esses materiais são utilizados, os alunos podem se prender a aspectos secundários, como as cores das peças do ábaco. Também indica que essa interlocução e as "interessantes cutucadas" dos acadêmicos modificaram o 
modo como compreendia o conceito de fração. Essa parceria - ele compreende - é constituída em vias de mão dupla, da seguinte maneira:

Os professores universitários têm um conhecimento teórico maior, que podem justificar elou dar apoio às nossas práticas de sala, o que permite ter um novo olhar sobre nossos alunos e pensar em novas práticas. De outro lado, permite ao professor universitário conhecer a realidade das escolas através dos professores da escola básica e assim rever a formação dos futuros professores. (Prof. Roberto, entrevista).

As percepções de Roberto vêm ao encontro dos estudos que dizem que professores em comunidades "têm negociado significados e perspectivas com os formadores e os acadêmicos da universidade sobre questões da prática pedagógica em matemática e do trabalho docente nas escolas públicas no contexto atual" (FIORENTINI, 2009, p. 234-235).

Sobre o que mobiliza sua participação no grupo, resume: "Acho que participar de um grupo como o GdS implica ser questionado sempre. Estamos sempre sendo cutucados. Agora, se você sair dele e ficar só na escola, acaba ficando com alguns vícios. Queira ou não, esse modelo de escola nos sufoca." (Prof. Roberto, entrevista).

O que Roberto chama de "cutucadas", os acadêmicos chamariam de problematização/questionamento das práticas narradas pelos professores, provocando desnaturalização. Questionado sobre quais vícios seriam esses, esclarece:

De procedimento mesmo, de atitude que tem com os alunos, de julgar e de dizer que o culpado é o aluno e de não olhar para a própria aula. Mas, ai você vê que professores que têm essa postura têm uma jornada grande de Estado e Prefeitura, estão cansados. Às vezes têm quatro escolas. Se não tiver alguém cutucando, motivando.... Nessa escola, eu tenho vários professores que estão se aposentando. Eu até entendo, estão cansados. E sabem que mudanças dão trabalho. Preparar aula.... Eu até respeito a atuação docente deles. Mas, aí, se você não tem nada que incentive, acaba indo junto. (Prof. Roberto, entrevista).

Os sentidos atribuídos por Roberto à sua participação no grupo vêm ao encontro do que aponta Fiorentini (2013) sobre a necessidade de promover formação contínua que tenha como foco de estudo, análise e problematização das 
práticas de ensinaraprender dos professores envolvidos, sobretudo que contém com excedente de visão de outras comunidades como as dos acadêmicos, pois

[...] as práticas cotidianas (com seus procedimentos, discursos e conhecimentos) são carregados de valores, finalidades e saberes que, embora sejam plenos de sentido e significado para a formação e o desenvolvimento humanos, podem, devido à naturalização e à rotina das mesmas - como destaca Foucault (1977) - ter-se tornado naturais e válidas por si mesmas, ocultando desvios, ideologias e relações de poder. (FIORENTINI, 2013, p. 158).

Roberto, ao reconhecer a importância e o papel do GdS na problematização e desnaturalização das práticas, resume, dizendo que "gostaria de ter mais tempo para se dedicar aos estudos em comunidades como do GdS". Reconhece que os questionamentos no âmbito do GdS promovem aprendizagens que vão além do ensino da matemática ou de sua sala de aula. Afirma que, ao olhar para o contexto das práticas escolares, "temos uma visão mais ampla do ensino. De repente, eles resolvem fechar uma sala, então passei a procurar o 'porquê'. Eu acho que, ao participar do grupo, aprendi a ter essa visão do geral para questionar políticas públicas que afetam minha prática" (Prof. Roberto, entrevista).

As percepções do professor sobre o grupo vêm ao encontro do que defendem Cochran-Smith e Lytle (1999), quando destacam que professores precisam trabalhar em conjunto para investigar suas próprias suposições, o modo como ensinam, bem como, o desenvolvimento do currículo, as práticas e políticas públicas.

Roberto também destaca, como aprendizagem no grupo, que "podemos e devemos lutar para ter uma política pública de ensino adequada à realidade e que é possível conseguir mudanças através desta luta”. E, em outra ocasião, Roberto sintetiza a razão pela qual continua participando do Grupo: "eu continuo participando do GdS para não me esquecer de quem eu sou”. Na escola, revelou que "não tenho o controle que a outra professora tem, mas gosto de ganhar meu aluno pelo lado humano".

Anos mais tarde, Roberto, motivado pela prática colaborativa que encontrou no GdS, constituiu com as professoras dos anos iniciais de sua escola um pequeno grupo colaborativo. Essa função de formador de professores em serviço faz parte de sua jornada atual de trabalho e consiste no desenvolvimento e no estudo de atividades matemáticas com as professoras, envolvendo conversas, estratégias, formação conjunta, planejamento curricular e de aula e desenvol- 
vimento de atividades com os alunos do ciclo (entrevista). Os resultados desse trabalho colaborativo foram apresentados por Roberto, em 2010, ao participar de uma mesa-redonda no III Seminário de Histórias e Investigações de/em Aulas de Matemática (SHIAM).

Durante a entrevista, Roberto também citou uma série de espaços e comunidades que fazem parte de seu cotidiano. Ao discutir as fronteiras das comunidades de prática, Wenger (2001, p. 135) aponta que essas não podem ser compreendidas como isoladas do mundo, uma vez que "suas histórias não são internas, mas de articulação com o resto do mundo". De acordo com esse pesquisador, é pela participação e pela coisificação em comunidades de práticas que se pode contribuir para a descontinuidade de limites.

Nos últimos anos, a parceria de Roberto com as professoras dos anos iniciais foi interrompida, pois algumas classes em que atuava foram fechadas e Roberto precisou completar sua carga em outra escola, o que o impossibilitou de continuar a contribuir com suas colegas. As notícias mais recentes são de que Roberto já se encontra adaptado à nova escola, uma escola pequena, como gosta de frisar, em que pode conhecer seus alunos desde "pequetititos".

Sobre seu sonho como professor, na primeira entrevista, Roberto destacou que "é conseguir fazer meus alunos gostarem de matemática". Em particular, como projeto, revela que gostaria de continuar realizando o trabalho com o grupo dos anos iniciais. Ao final da entrevista, ele se lembrou das falas de um acadêmico sobre Bakhtin. Segundo Roberto, a autoria do que falamos vem dos outros, fazendo a seguinte síntese: "a ideia de Bakhtin é que a minha fala, na verdade, não é minha, mas é resultado da fala dos outros e que eu me aproprio das palavras dos outros e, na interação com estas, surge o que falo" (Prof. Roberto, entrevista).

\section{Algumas conclusões e considerações finais}

Ao longo da narrativa de Roberto, é possível notar indícios de que, ao compartilhar experiências e participar de estudos e investigações em uma comunidade fronteiriça, como é o GdS, produziu outros sentidos e significados à prática de ensinar e aprender matemática na escola. Nessa comunidade e mediante interação com colegas com diferentes visões e experiências, constituiu-se sujeito de seu próprio desenvolvimento profissional, assumindo características de uma profissionalidade com postura de questionamentos sobre sua prática na 
escola. Além disso, apresentou fortes indícios de mudança nos rumos de seu trabalho como docente de matemática.

Uma das reverberações da aprendizagem de Roberto, na comunidade fronteiriça do $\mathrm{GdS}$, diz respeito à sua própria constituição identitária, tendo sido possível vislumbrar modificações nos próprios modos de ser/estar como professor de matemática. Por exemplo, a emergência de uma postura de permanente questionamento e problematização - como assinalam Cochran-Smith e Lytle (2009) - sobre a própria prática, sobre as políticas públicas que a condiciona e, também, sobre as possibilidades e os limites dos conhecimentos curriculares e didático-pedagógicos.

Por outro lado, a reverberação do que aprendeu na comunidade fronteiriça trouxe implicações e mudanças na cultura de sua escola, tendo constituído uma pequena comunidade escolar colaborativa com os colegas dos anos iniciais do ensino fundamental. Essa comunidade tinha como prática formativa discutir e analisar possibilidades de melhoria do ensino e da aprendizagem matemática, além de incrementar o conhecimento especializado do professor que ensina matemática nesse nível de ensino.

\section{REFERÊNCIAS}

BAKHTIN, M. Estética da criação verbal. Trad. Paulo Bezerra. São Paulo: Martins Fontes, 2011.

BARBUTTI, A. R.; PROENÇA, H. H. D. M.; CRECCI, V. M. Tramas de um Professor de Matemática e a Colaboração do Grupo de Sábado (GdS). In: GONÇALVES JÚNIOR, M. A.; CRISTOVÃO, E. M.; LIMA, R. C. R. de (Org.). Grupos Colaborativos e de Aprendizagem do Professor que Ensina Matemática: repensar a formação de professores é preciso! Campinas: FE-Unicamp, 2014. v. 1, p. 1-164.

BONDÍA-LARROSA, J. Narrativa, identidad y desidentificación. La experiencia de la lectura. Barcelona: Laertes, 1996.

CARVALHO, D. L.; FIORENTINI, D. Refletir e investigar a própria prática de ensinaraprender matemática na escola. In: CARVALHO, D. L.; MARTINS, C. A. C. L.; FIORENTINI, D. (Org.). Análises narrativas de aulas de matemática. 1. ed. São Carlos: Pedro \& João Editores, 2013. v. 1, p. 11-23. 
CLANDININ, D. J.; HUBER, J. Narrative inquiry. In: McGAW, B.; BAKER, E.; PETERSON, P. P. (Eds.). International Encyclopedia of Education. 3. ed. New York, NY: Elsevier, 2010. p. 436-441.

CLANDININ, D. J.; CONNELLY, F. M. Pesquisa narrativa: experiência e história em pesquisa qualitativa. Tradução: Grupo de Pesquisa Narrativa e Educação de Professores ILEEI/UFU. Uberlândia: EDUFU, 2011.

COCHRAN-SMITH, M.; LYTLE, S. L. Relationships of knowledge and practice: Teacher learning in communities. Review of Research in Education, Washington, v. 24, p. 249-305, 1999.

COCHRAN-SMITH, M.; LYTLE, S. L. Teacher Learning Communities. In: GUTHRIE, J. (Ed.). Encyclopedia of Education. 2. ed. New York: Macmillan, 2002.

COCHRAN-SMITH, M.; LYTLE, S. L. Inquiry as Stance: Practitioner Research in the Next Generation. New York: Teachers College Press, 2009.

CRECCI, V. M. Desenvolvimento profissional de educadores matemáticos participantes de uma comunidade fronteiriça entre escola e universidade. 2016. 325 f. Tese (Doutorado em Educação) - Universidade Estadual de Campinas, Campinas, 2016.

FIORENTINI, D. Quando acadêmicos da universidade e professores da escola básica constituem uma comunidade de prática reflexiva e investigativa. In: FIORENTINI, D.; GRANDO, R. C.; MISKULIN, R. G. S. (Org.). Práticas de formação e de pesquisa de professores que ensinam matemática. 1. ed. Campinas: Mercado de Letras, 2009. v. 1, p. 233-255.

FIORENTINI, D. Learning and Professional Development of the Mathematics Teacher in Research Communities. Sisyphus - Journal of Education, v. 1, p. 152-181, 2013.

FIORENTINI, D.; OLIVEIRA, A. T. C. C. O lugar das matemáticas na Licenciatura em Matemática: que matemáticas e que práticas formativas? Bolema, v. 27, n. 47, p. 917-938, 2013.

LAVE, J.; WENGER, E. Situated learning: legitimate peripheral participation. New York: Cambridge University Press, 1991.

LAVE, J.; WENGER, E. Prática, Pessoa, Mundo Social. In: DANIELS, H. (Org.). Uma introdução a Vygotsky. São Paulo: Edições Loyola, 2002.

MARQUESIN, D. F. B.; PASSOS, L. F. Narrativa como objeto de estudo: aportes teóricos. Revista Múltiplas Leituras, v. 2, n. 2, p. 219-237, jul./dez. 2009.

PINTO, R. A. Quando professores de Matemática tornam-se produtores de textos escritos. 2002. 246 f. Tese (Doutorado em Educação) - Universidade Estadual de Campinas, Campinas, 2002. 
WENGER, E. Comunidades de Practica - Aprendizaje Significado e Identidad. Paidos Iberica, Ediciones S. A., June 2001.

WENGER-TRAYNER, E.; WENGER-TRAYNER, B. Learning in Landscapes of Practice: a framework. In: WENGER-TRAYNER, E. et al. Learning in landscapes of practice boundaries, identity and knowledgeability. London, United Kingdom: Routledge, 2016.

Texto recebido em 07 de fevereiro de 2018. Texto aprovado em 13 de março de 2018. 